\title{
Interlayer Bonding Energy of Mg-Chlorite: A Density Functional Theory Study
}

\author{
Hiroshi SAKUMA $^{*}$ \\ National Institute for Materials Science, 1-1 Namiki, Tsukuba, Ibaraki 3050044 \\ *e-mail:SAKUMA.Hiroshi@nims.go.jp
}

\begin{abstract}
(Received: March 23, 2015; Accepted for publication: May 22, 2015; Online publication: July 17, 2015)
Interlayer bonding energy (ILBE) of Mg-chlorite was calculated based on the density functional theory with dispersion force correction (DFT-D2). The calculated ILBE of Mg-chlorite was smaller than brucite, phlogopite, gibbsite, and muscovite and was comparable to talc, kaolinite, pyrophyllite, and lizardite. The attractive interaction between layers would be generated by the weak hydrogen bond between layers. The ILBE of Mg-chlorite should be the minimum ILBE in natural chlorite group, since the natural chlorite shows the isomorphic substitution which induces high layer charge resulting in stronger attractive interaction between layers like phlogopite and muscovite.
\end{abstract}

Keywords: Separation energy, Friction, Clay mineral, Chlorite, DFT

\section{Introduction}

Chlorite is an important mineral for understanding the friction in natural faults. Drilling cores recovered from off the Kii Peninsula, central Japan were composed of clay-mineral matrix with plagioclase and clinopyroxene phenocrysts [1]. The major clay mineral was saponite and this saponite would be altered to chlorite after entering the subduction zone of the Nankai Trough by the movement of Philippine Sea Plate. This hypothesis is supported by the presence of chlorite in ancient subduction thrust exposed in the Shimanto accretionary complex [2]. Therefore the frictional property of chlorite may be potentially important for the fault slip in the Nankai Trough.

Maximum friction coefficient of layered minerals has been interpreted by a linear relationship with the interlayer bonding energy (ILBE) [3]. However, recent friction experiments [4] and reliable ILBEs calculated by first-principles density functional theory (DFT) study [5] cannot confirm such linear relationship with the friction coefficients. Natural minerals used in shear experiments have variation in their chemical compositions, therefore, reliable ILBEs for layered minerals should be calculated with various chemical compositions for testing the hypothesis of the linear relationship.
In this study, we tried to derive the ILBE of pure Mg-chlorite which is an end member of chlorite. This is the first step for deriving the ILBE of complex natural chlorite having variable chemical composition by isomorphic substitution.

\section{Materials and Computational Method}

Mg-chlorite $\left(\mathrm{Mg}_{6}(\mathrm{OH})_{8}\left[\mathrm{Si}_{4} \mathrm{O}_{10}\right]\right)$ is composed of a brucite layer $\left(\mathrm{Mg}(\mathrm{OH})_{2}\right)$ sandwiched by talc $\left(\mathrm{Mg}_{3}(\mathrm{OH})_{2}\left[\mathrm{Si}_{4} \mathrm{O}_{10}\right]\right)$ layers as shown in Figure 1. The cleavage plane of chlorite is characterized by (001) and the ILBE of chlorite was calculated for this plane. The lattice constant of Mg-chlorite was calculated before calculating the ILBE for confirming the reliability of our DFT calculations. The exchange-correlational functional has been expressed by the generalized gradient approximation (GGAPBE) [6]. Pseudopotential method [7,8] was employed for reducing the computational cost. $\mathrm{Mg}$ ion was partly considered for the effect of the core electron by a nonlinear core correction method [9]. Cut-off energy of plane waves was 60 Ry for wavefuctions and 480 Ry for electron density. K-point sampling was conducted by Monkhorst-Pack method [10]. The $4 \times 2 \times 1 \mathrm{k}$ point mesh was used for both bulk and ILBE calculations. The empirical dispersion force correction (DFT-D2) [11] was used 


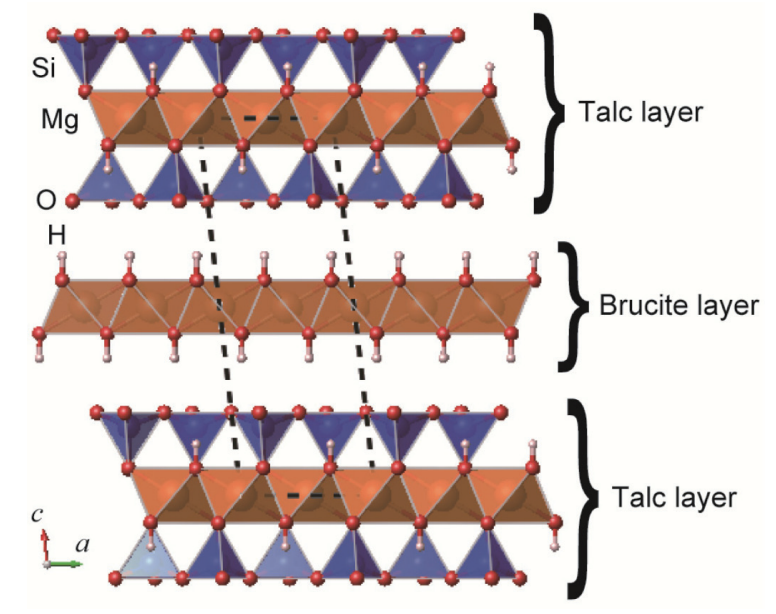

Figure 1. Structure of Mg-chlorite. Dashed line indicates the unit cell.

for all calculations. We confirmed that no significant difference was noted for the ILBEs calculated by the other dispersion correction schemes such as DFT-D2, D3, and vdW-DF (optB86b$\mathrm{vdW}$ ) [5]. The ILBE of Mg-chlorite was calculated by the same procedure as our previous studies $[5,12]$. Briefly, the ILBE $E_{\mathrm{I}}$ LBE was obtained by the total energy of supercell including one brucite layer and one talc layer $E_{\text {chlorite }}$ subtracted by the energies of one brucite layer placed in a supercell $E_{\text {brucite }}$ and one talc layer placed in a supercell $E_{\text {talc }}$ (Figure 2) as follows.

$$
E_{\mathrm{ILBE}}=E_{\text {chlorite }}-E_{\text {brucite }}-E_{\text {talc }} \text {. }
$$

To remove the effect of dipole field generated by using periodic boundary condition normal to (001), a vacuum (20 $\AA$ ) was imposed in the supercell and the dipole was corrected by a standard procedure [13]. 72 atoms were included in the supercell for calculating the $E_{\text {chlorite }}$. The criteria of total energy $(<0.1$ $\mathrm{mRy})$ and force convergence $(<0.1 \mathrm{mRy} / \mathrm{bohr})$ were applied to calculate the relaxed structure for obtaining the ILBE. The stress criterion for bulk calculations was set to $<0.5 \mathrm{kbar}$. All calculation was performed by Quantum-ESPRESSO code [14].

\section{Results and Discussion}

\subsection{Lattice constants and structure of Mg-chlorite}

Structure optimization was performed for Mg-chlorite. The relaxed structure was shown in Figure 1.

Calculated cell parameters were listed in Table 1. The difference of cell parameters from the experimental results $[15,16]$

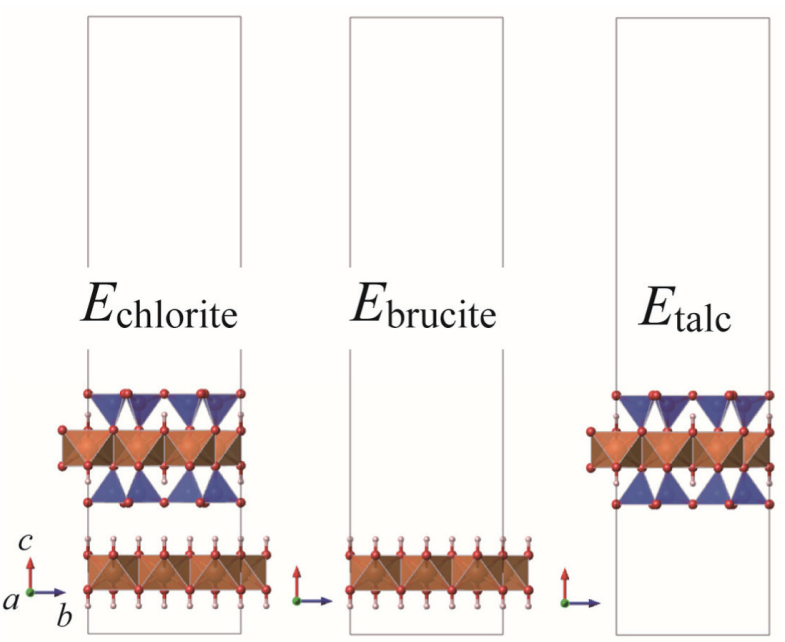

$$
E_{\mathrm{ILBE}}=E_{\text {chlorite }}-E_{\text {brucite }}-E_{\text {talc }}
$$

Figure 2. Schematic diagram explaining the method of calculation for the interlayer bonding energy (ILBE) of Mg-chlorite. The solid squares indicate the supercells.

Table 1. Lattice constants of Mg-chloride.

\begin{tabular}{ccc}
\hline Lattice constants & $\begin{array}{l}\text { DFT-D2 } \\
\text { (Difference from Exp.) }\end{array}$ & Exp [15]. \\
\hline$a[\AA]$ & $5.3174(-0.4 \%)$ & 5.3363 \\
$b[\AA]$ & $9.2099(-0.3 \%)$ & 9.2400 \\
$c[\AA]$ & $14.9608(1.1 \%)$ & $14.7950^{*}$ \\
$\beta\left[^{\circ}\right]$ & $96.50(-0.5 \%)$ & 96.93 \\
\hline
\end{tabular}

$*_{c}$ length depends on the degree of isomorphic substitution [16]. The value corresponds to the $c$ parameter of pure Mg-chlorite.

was less than $1.1 \%$. Therefore we confirmed that the DFT-D2 method can evaluate the structure and ILBE of Mg-chlorite as similar layered silicates reported by previous studies $[5,12,17]$.

\subsection{Interlayer bonding energy (ILBE) of Mg-chlorite}

Calcultated ILBE of Mg-chlorite was plotted in Figure 3. The ILBEs of other layered minerals (pyrophyllite, talc, kaolinite, lizardite, gibbsite, brucite, muscovite, and phlogopite) [5] were shown as a comparison. The structure of the cleavage plane of Mg-chlorite was similar to that of lizardite. The ILBE of lizardite $\left(\mathrm{Mg}_{3}(\mathrm{OH})_{4}\left[\mathrm{Si}_{2} \mathrm{O}_{5}\right]\right)$ is characterized by the interaction between $\mathrm{SiO}_{4}$ tetrahedral and brucite layers, and the value of ILBE is similar to the Mg-chlorite. Therefore the calculated 


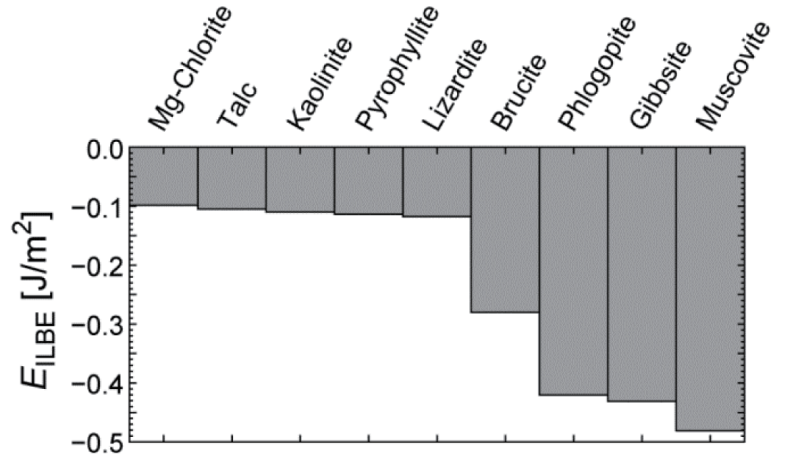

Figure 3. Interlayer bonding energy $\left(E_{\mathrm{ILBE}}\right)$ of Mg-chlorite calculated by DFT-D2 method. The $E_{\mathrm{ILBE}}$ of other layered minerals calculated by the same method [5] was plotted for a comparison.

ILBE of Mg-chlorite should be reasonable. The ILBE of Mgchlorite was comparable with lizardite, talc, kaolinite, and pyrophyllite. The ILBEs of these minerals are characterized by the weak van der Waals and/or hydrogen-bonding interaction between the layers. Large ILBEs of brucite and gibbsite can be explained by the strong hydrogen bonds between the layers. Phlogopite and muscovite have structural negative layer charge and the layers were bonded by interlayer cations. Therefore, the large ILBEs of these minerals are characterized by the strong Coulomb interaction between the layers. It should be noted that many natural chlorites show partial isomorphic substitutions of $\mathrm{Si}$ and $\mathrm{Mg}$ to $\mathrm{Al}$ and Fe, respectively. Such isomorphic substitution increases the layer charge in talc layers. X-ray diffraction measurements showed that the interlayer distance decreased with increasing isomorphic substitution [16] implying the increased attractive interaction between the layers. Therefore, the calculated ILBE for Mg-chlorite should be the minimum for trioctahedral chlorite group. This speculation should be confirmed in future works.

\section{Concluding Remarks}

In this study, we calculated the interlayer bonding energy (ILBE) of Mg-chlorite by using the DFT calculations with empirical dispersion force correction. The ILBE of Mg-chlorite was similar to that of lizardite having the similar interlayer structure. Most natural chlorite shows a certain isomorphic substitution and this substitution would increase attractive interaction between layers. Therefore the calculated ILBE of
Mg-chlorite should be the weakest value for trioctahedral chlorite group. In future work, the effect of isomorphic substitution should be investigated for further discussion.

Computer resources were provided by the clusters at the National Institute of Materials Science. The structure of Mg-chlorite was partly drawn by using VESTA [18].

\section{References}

[1] J. Kameda, A. Yamaguchi, S. Saito, H. Sakuma, K. Kawamura, G. Kimura, Geophys. Res. Lett., 38, L22306 (2011). [CrossRef]

[2] J. Kameda, K. Ujiie, A. Yamaguchi, G. Kimura, Earth Planet. Sci. Lett., 305, 161 (2011). [CrossRef]

[3] D. E. Moore, D. A. Lockner, J. Geophys. Res., 109, B03401 (2004). [CrossRef]

[4] J. Behnsen, D. R. Faulkner, J. Struct. Geol., 42, 49 (2012). [CrossRef]

[5] H. Sakuma, S. Suehara, J. Geophys. Res. Solid Earth, 120, 2212 (2015).[CrossRef]

[6] J. P. Perdew, K. Burke, M. Ernzerhof, Phys. Rev. Lett., 77, 3865 (1996). [Medline] [CrossRef]

[7] A. M. Rappe, K. M. Rabe, E. Kaxiras, J. D. Joannopoulos, Phys. Rev. B, 41, 1227 (1990). [CrossRef]

[8] D. Vanderbilt, Phys. Rev. B, 41, 7892 (1990). [CrossRef]

[9] S. G. Louie, S. Froyen, M. L. Cohen, Phys. Rev. B, 26, 1738 (1982). [CrossRef]

[10] H. J. Monkhorst, J. D. Pack, Phys. Rev. B, 13, 5188 (1976). [CrossRef]

[11] S. Grimme, J. Comput. Chem., 27, 1787 (2006). [Medline] [CrossRef]

[12] H. Sakuma, J. Geophys. Res. Solid Earth, 118, 6066 (2013). [CrossRef]

[13] L. Bengtsson, Phys. Rev. B, 59, 12301 (1999). [CrossRef]

[14] P. Giannozzi, et al., J. Phys. Condens. Matter, 21, (2009). [CrossRef]

[15] P. F. Zanazzi, M. Montagnoli, S. Nazzareni, P. Comodi, Am. Mineral., 92, 655 (2007). [CrossRef]

[16] G. Brown, G. W. Brindley, in Mineralogical Society Monograph No. 5, Crystal Structures of Clay Minerals and Their X-Ray Identification, edited by G.W. Brindley and G. Brown, 305 (1984).

[17] D. Tunega, T. Bučko, A. Zaoui, J. Chem. Phys., 137, 114105 (2012). [Medline] [CrossRef]

[18] K. Momma, F. Izumi, J. Appl. Cryst., 41, 653 (2008). [CrossRef] 